\title{
Religious Organizations
}

\section{Gilat Levy and Ronny Razin*}

Discussion Paper No. TE/2009/544

November 2009

The Suntory-Toyota International Centres for

Economics and Related Disciplines

London School of Economics and Political Science

Houghton Street

London WC2A 2AE

Tel.: 020-7955 6674

* Department of Economics, LSE. Email: g.levy1@lse.ac.uk; r.razin@lse.ac.uk. We thank Stephen Hansen for valuable research assistance. We thank the ESRC (grant number RES-000-22-1856) and the ERC (grant number 210385) for financial support. 


\begin{abstract}
We propose a model of religious organizations which relies on the ability of such organizations to affect individual beliefs about the causality between actions in the social context and personal utility shocks. We show how religious organizations arise endogenously and characterize their features. Specifically, we find that members of the religious organization share similar beliefs and are more likely to cooperate with one another in social interactions. We identify a "spiritual" as well as a "material" payoff for members of the religious organization. Our results explain and shed light on empirical phenomena such as the effects of secularization and economic development on religious beliefs and participation, the relation between the size of the religion and the intensity of its members' beliefs, religious segregation and religious conflicts.
\end{abstract}

(c) The authors. All rights reserved. Short sections of text, not to exceed two paragraphs, may be quoted without explicit permission provided that full credit, including $\odot$ notice, is given to the source. 


\section{Introduction}

The role of religion in society has recently been the subject of renewed empirical and experimental interest. In particular, the literature focuses on how religious beliefs and religious practice affect various parameters, ranging from micro data such as individuals' well-being and individual behaviour (Gruber 2003, Sosis and Ruffle 2003), to macro parameters such as growth (Barro and McCleary 2003, Guiso, Sapeinza and Zingales 2003) and the provision of state social insurance (Stasavage and Scheve 2006).

Religious beliefs and religious practice are clearly two important and possibly inseparable features of religious organizations. The study of religious beliefs however has largely been neglected in the economic literature on religion. ${ }^{2}$ In this paper we propose a theory of religious organizations that focuses on the ability of such organizations to affect individuals' beliefs. In our theory, religious beliefs and religious practice are determined together; this allows us to derive predictions on the link between them, as well as to shed light on some of the recent findings in the literature.

We consider a society in which individuals are randomly paired to play a one-shot symmetric Prisoner's Dilemma (PD) game. Following the strategic interaction, individuals experience shocks to their well-being. In our model, religious beliefs will be defined by a statistical relation (possibly guided by some supernatural entity) between an individual's behaviour in the social context and his likelihood to experience these negative or positive utility shocks. Examples of such systems of religious beliefs are abundant in the Anthropological literature. ${ }^{3}$ Concepts of rewards and punishments for one's deeds, in an individual or in a social context, in this life or the afterlife, exist in the Abrahamic religions as well as in the Eastern ones, such as Buddhism (Karma and Vikapa) and Hinduism (where Papa refers to social actions that create negative karma), among others. ${ }^{4}$

Religious organizations play an active role in shaping beliefs; many invest time and effort in advocating certain kinds of messages while censoring others. ${ }^{5}$ Our main assumption is that an

\footnotetext{
${ }^{2}$ Some exceptions are Benabou and Tirole (2006) and Bisin and Verdier (2001), which consider beliefs (but do not explicitly model religious organizations).

${ }^{3}$ Evans-Pritchard (1956) writes on the Nuer in Sudan: "...and in any argument about conduct the issue is always whether a person has conformed to the accepted norms of social life....the Nuer are of one voice in saying that sooner or later good will follow right conduct and ill will follow wrong conduct.".

${ }^{4}$ Note that religious belief systems are sometimes more complex, e.g., conditioning consequences also on the behavior of others. We discuss more complex belief systems in Section 5 .

${ }^{5}$ One example of censorship is the Index Librorum Prohibitorum ("List of Prohibited Books") (from 1529 to 1966) which listed publications prohibited by the Roman Catholic Church.
} 
individual's affiliation with a religious organization endows him with religious beliefs. We also assume that different individuals have different propensities to be affected by such religious preaching. ${ }^{6}$ Those who are not affiliated with a religious organization, i.e., seculars, see no statistical relation between their actions in the PD game and the shocks to their utility.

Finally, we assume that individuals who belong to the religious organization take part in some observable activity that we interpret as rituals. Religious participation thus has a duel role in our theory; it is a public activity that allows individuals to distinguish between different affiliations and it affects the beliefs of individuals about the causality of utility shocks.

We formalize an equilibrium notion of stable religious organizations in which no agent wishes to change her affiliation and behaviour given other individuals' affiliation choices and expected behaviour. Our first set of results establishes that stable religious organizations arise endogenously in equilibrium and characterizes their properties: Any organized religion always includes, and sometimes exclusively includes, individuals who believe that they are more likely to receive a negative shock when they defect rather than when they cooperate. In addition, religious individuals are more cooperative towards fellow religious members than they are towards seculars. Finally, we find that whenever some agents in society are secular, religious participation (rituals) must be costly. ${ }^{7}$

In our model, the benefit from being religious (versus secular) is composed of a "material" and a "spiritual" component. The spiritual component arises as religious individuals behave more cooperatively, which, given their beliefs, will bring about good fortune in the future. Only religious individuals can be motivated by the spiritual payoff as only they can potentially believe that cooperation yields rewards. The material benefit of becoming religious, which can motivate all individuals, arises as relative to seculars, religious individuals enjoy a higher level of cooperation in social interactions.

The material benefit of religion identified in our model is supported by empirical studies showing a link between religious participation, social ties and mutual assistance. ${ }^{8}$ It is also an important distinction between our approach and previous ones. The economic literature

\footnotetext{
${ }^{6}$ The heterogeneity of individual propensities to be affected by religious preaching is motivated by the Evolutionary Biology literature. Boyer (2001) summarizes how different evolutionary strategies might create different types of "religious centres" in the human mind.

${ }^{7}$ Barro and McCleary (2003) find that economic growth responds positively to religious beliefs but negatively to religious participation. Our model implies a positive relation between religious beliefs and cooperative behaviour, which may enhance economic growth. Also, as we find that rituals are costly, religious participation could be an impediment to growth.

${ }^{8}$ See for example Wilson (2002) and Bradley (1995). Ellison and George (1994) find a positive relationship between religious participation and social ties in a survey of 2,956 households in the southeastern United States.
} 
on religion has mainly focused on spiritual motivations for becoming religious. For example Iannaccone (1992), Stark (1996) and Berman (2000), among others, are all based on the premise that individuals have a demand for spiritual goods, and that religious organizations are the providers of such goods. We find that the material benefit provided by the religion, through enhanced internal cooperation, is in some cases sufficient to outweigh the cost of religious participation - which implies that religion can be beneficial to everyone in society.

Our second set of results establishes the relation between the intensity of rituals, the beliefs and behaviour of religious individuals, and the size of the religion. In particular, we find that religious groups that are more demanding in their rituals are smaller, more cohesive (that is, their members behave more cooperatively towards one another), and are composed of individuals whose beliefs are more "extreme" about the relation between unsocial behaviour and punishment. Moreover, when several religious organizations arise in equilibrium, the smaller and more conservative religions are less cooperative towards the larger and less conservative ones, thus creating a "hierarchy" of religions (or denominations within religions). These predictions finds support in the empirical studies of Iannaccone $(1992,1994,1998)$, and in several experimental studies (see Orbell et al 1992 and Sosis and Ruffle 2003).

We next analyze the effects of modernization on religious participation and beliefs. The Weberian view posits that with scientific progress the role of religious organizations in society will diminish over time. Durkeim has suggested that their role will diminish with economic development, as state and economic institutions will provide material benefits in their stead. Our framework allows us to analyze these hypotheses. We find that the effects of modernization on religion are not neccesarily monotone. While for small cohesive religions, scientific progress decreases participation and increases the intensity of the remaining participants' beliefs and rituals, it does not necessarily decrease participation in large religions which provide substantial material benefits. On the other hand, economic development indeed lowers participation and intensity of beliefs for most types of religious organizations. ${ }^{9}$

Finally, we examine the dynamic evolution of religious organizations in response to correlated utility shocks such as economic booms, recessions or natural disasters. In such occasions individuals can update their beliefs about the causality of welfare shocks. We find that correlated positive utility shocks cause beliefs to polarize, inducing deconversions and as a result a reduction in the size of the religion. In contrast, negative shocks may yield both conversions and deconversions, with an ambiguous effect on the size of religious organizations. While sev-

\footnotetext{
${ }^{9}$ Our results can help interpret Huber (2005) who shows that in more developed countries, church goers become more conservative, "non believers" stop attending church, and "network" effects are less important.
} 
eral empirical studies have examined how religiosity may allow individuals to cope with bad news, to our knowledge few have investigated how bad or good outcomes affect religiosity (see Chen (2008)).

The remainder of the paper is organized as follows. In the next section we present the model. In Section 3 we present our main results about religious organizations in equilibrium, including a discussion of welfare properties and comparative statics. In the first extension of our model, in Section 4, we consider the different ways in which competition between religious groups manifests itself and show that religious conflicts may arise as a tool to increase group membership. In Section 5 we consider a dynamic extension; we analyse the ability of religious organizations to survive in the long run, shedding light on aspects such as the "afterlife" and "forgiveness", as well as religious segregation. An appendix contains all proofs.

\section{The model}

We consider a society in which individuals are paired to play a Prisoner's Dilemma (PD) game. Some individuals are secular and some are religious. Being religious is related to two (inseparable) features: participation in a costly and observable activity, and having certain beliefs about the statistical relation between actions in the PD game and private utility shocks. Given the observable religious activity, individuals can condition their behaviour in the PD game on their opponent's affiliation. Our notion of equilibrium will involve optimal behaviour in the PD game and a stability condition on individuals' affiliation choices. We now explain the model in more detail.

The social interaction. Individuals are randomly paired to play a one-shot PD game:

\begin{tabular}{|l|l|l|}
\hline & $\mathrm{C}$ & $\mathrm{D}$ \\
\hline $\mathrm{C}$ & $d, d$ & $c, b$ \\
\hline $\mathrm{D}$ & $b, c$ & $a, a$ \\
\hline
\end{tabular}

where $b>d>a>c$. We assume strategic complements, i.e., that $d-b>c-a$. This assumption is the standard one in the literature on cooperation in such games.

Social rituals. Being religious is associated with some observable action, with a cost $r$ ( $r$ can be either positive or negative). An individual that has paid the cost $r$ is "religious", otherwise he is "secular". We interpret these observable actions as religious rituals. We consider rituals, such as attendance in religious sermons, which not only allow group members to identify and familiarize themselves with one another but may also have an effect on the 
beliefs of individuals, as we describe later on. ${ }^{10}$

Utility shocks. We assume that following the strategic interaction, each individual believes he will receive, in addition to the payoffs of the PD game, either a negative utility shock, $-\varepsilon$, or a positive utility shock, $\varepsilon$. Apart from participation in rituals, we differentiate between seculars and religious individuals also according to their beliefs about the relationship between the shocks and their actions in the PD game, as we now explain.

Beliefs. We assume that seculars believe that there is no relation between actions taken in the PD game and utility shocks. They view the social interaction as the "material" PD game and hence their best response is to defect. Religious individuals on the other hand believe that there is some pattern determining the shocks, and that this pattern depends on their actions in the PD game. One interpretation for such beliefs is that the shocks are the intentional actions of some supernatural entity which rewards or punishes individuals according to their behaviour.

Specifically, each individual $i$ in the population is endowed with a type reflecting his propensity to be affected by religious participation. In particular, individual $i^{\prime} s$ type, $\left(q_{c}^{i}, q_{d}^{i}\right)$, represents his beliefs when he is religious. That is, a religious individual believes that when he cooperates, he receives the negative shock with probability $q_{c}^{i} \in[0,1]$ and that when he defects, he receives the negative shock with probability $q_{d}^{i} \in[0,1]$. Note that this formulation allows for individuals not to be affected by religious participation; a religious individual with $q_{c}^{i}=q_{d}^{i}$ does not believe that his actions in the social game have any statistical effect on the type of shock he will experience.

We assume risk neutrality and thus the expected utility of a religious individual who cooperates is $x+\varepsilon\left(1-2 q_{c}^{i}\right)$, for $x \in\{c, d\}$ (depending on his rival's action), and similarly, the expected utility of a religious individual who defects is $x+\varepsilon\left(1-2 q_{d}^{i}\right)$, for $x \in\{a, b\}$.

It will be sufficient, as will become apparent later on, to characterize the types in the population by the parameter $q^{i}=q_{c}^{i}-q_{d}^{i}$, where the higher is $q^{i}$, the less a religious individual fears that defection will lead to punishment. Note that the dominant action of a religious individual with $q^{i} \geq \bar{q}=\frac{d-b}{2 \varepsilon}$ is to defect in the PD game, whereas the dominant action of a religious individual with $q^{i} \leq \underline{q}=\frac{c-a}{2 \varepsilon}<\bar{q}$, is to cooperate, with both $\bar{q}$ and $\underline{q}$ strictly negative. The best response of those with $q^{i} \in(\underline{q}, \bar{q})$, henceforth "intermediates", is to cooperate if their opponent does, and defect otherwise.

As types with $q^{i}>0$ will play no role in the results, we focus on types in $[-1,0]$. Let these

\footnotetext{
${ }^{10}$ In an alternative model, agents might also choose whom to interact with, conditional on whether he had paid the cost or not. We discuss this possibility in Section 5.
} 
types be distributed on $[-1,0]$ according to some continuous distribution function $F($.$) , with$ density $f$ satisfying $0<f()<.\infty$ everywhere. We assume that $F($.$) is common knowledge but$ that individuals do not observe the belief $q^{i}$ of their religious opponent $i .{ }^{11}$ Finally, we assume that shocks are important enough so that both $\bar{q}$ and $q$ are in the support of the population, i.e., that $\underline{q}=\frac{c-a}{2 \varepsilon}>-1$.

Equilibrium notion. We focus on the case in which there is only one organized religion in society (for other cases see Section 4 ). For any $(r, F)$, we look at a configuration of affiliation and PD strategy choices, and check whether it is stable.

Our equilibrium definition consists therefore of two main conditions. First, individuals must optimally choose how to play in the social interaction. As paying $r$ is observable, the strategy of an individual in the PD game may depend on whether his (randomly matched) opponent is religious or not.

Second, individuals' affiliations are optimal, that is, the religious must prefer to be religious, while seculars must prefer to be secular, given others' behaviour and affiliations. This equilibrium requirement is more subtle, as we need to determine how individuals evaluate counterfactual affiliation choices. We make two assumptions. We assume that an individual evaluates both affiliations given his current beliefs (i.e., $q^{i} \in[-1,0]$ for the religious, and the belief that there is no relation between shocks and actions for seculars). This assumption accords with the "partial empathy" approach, i.e., when parents use their own preferences to evaluate their children's welfare (see Tabellini (2007), Bisin and Verdier (2001) and Benabou and Tirole (2006)). We also assume that individuals anticipate that their beliefs will change once they switch their affiliation. Relaxing this assumption will not change the qualitative nature of our results.

Formally, equilibria in the model satisfy the following conditions:

1. (Optimal behaviour in the social interaction): Given the affiliation choices, and individual beliefs, the strategies in the PD game are best responses.

2. (Optimal affiliation): Given the strategies in the PD game, and their current beliefs, a religious individual $i$ prefers to be religious than to be secular (and defect) and a secular individual $i$ prefers to be secular than to be religious (and behave according to $q^{i}$ ).

\footnotetext{
${ }^{11}$ We maintain the assumption that there is no restriction imposed on the personal beliefs of agents given their knowledge of the distribution of beliefs in society at large. This is motivated either by an assumption of non-common priors or by assuming that agents believe that there is no statistical relation between their parameters, $q_{c}^{i}$ and $q_{d}^{i}$, and others' parameters.
} 
3. (Maximizing religious participation): There is no secular individual, such that if he becomes religious, strictly prefers to stay religious.

The third requirement is motivated by a surplus maximizing incentive of religious organizations. The assumption is that if there exists an individual that may be converted, the religious organization is able to do so. This refinement does not change the qualitative structure of religious organizations but rather selects the "largest" possible group for any $r$.

Notation and preliminaries: Finally, we introduce some notation. First, let $\rho$ be the share of the religious in society (with $1-\rho$ being the share of seculars). Let $\gamma_{R R}$ be the probability that a randomly chosen religious individual cooperates when he meets another religious opponent. Similarly, let $\gamma_{R S}$ denote the probability that a randomly chosen religious individual cooperates when he meets a secular opponent. These probabilities (as well as $\rho$ ) are determined in equilibrium given the share and the strategies of the types who join the religion.

Note that given $\gamma_{R R}$, intermediate religious types in $\left[\underline{q}, q^{*}\right]$ for some $q^{*} \leq \bar{q}$ will cooperate against religious opponents and types above $q^{*}$ will defect against them (where a higher $\gamma_{R R}$ will induce a higher $q^{*}$ ). As all intermediates defect against seculars, we have that $\gamma_{R R} \geq \gamma_{R S}$, where a strict inequality would hold in equilibrium if some religious intermediates cooperate only against fellow religious opponents.

\section{Religion: beliefs, rituals and social behaviour}

In this section we provide our main results about religious organizations. First, Proposition 1 below establishes the existence of religion in equilibrium and summarizes its main features:

Proposition 1 For sufficiently low values of $r$, there exists an equilibrium with a religious organization. Any equilibrium with a religion is characterized by: (i) a cutoff $q^{\prime} \leq \bar{q}$ such that all agents with types $q^{i} \leq q^{\prime}$ are religious; (ii) $\gamma_{R R} \geq \gamma_{R S}>0$; (iii) $r>0$ whenever some agents are secular.

Proposition 1 provides the basis for our interpretation of equilibrium as a religious organization: It connects the three observed aspect of religious groups, namely, beliefs, social behaviour and rituals. In equilibrium, those who engage in costly activities typically believe that unsocial behaviour leads to "punishment". The behaviour of these individuals is more cooperative and more so among themselves. Finally, the Proposition provides a rationale as to why rituals are often costly activities. 
We now analyze religious organizations in more detail; we first provide equilibrium analysis and a taxonomy of religious organizations. Our analysis reveals how religions provide material benefits to their members; we discuss such benefits and their normative properties. We derive a monotonicity result on the link between intensity of rituals, the size of religions and their level of cooperation. Finally, we perform comparative statics analysis to consider the effects of scientific progress and economic development on religious participation.

\subsection{Equilibrium analysis}

To understand how the equilibria with religious organizations are determined, consider the benefit for an individual with affiliation $J \in\{R, S\}$ of being religious vs. being secular, $V_{J}\left(q^{i}\right)$. Such relative benefit depends on her current affiliation, or more precisely, on her current beliefs. It is computed as the difference in the expected utility of being in each affiliation, while abstracting from the cost $r$.

Consider first a religious individual who evaluates whether to stay religious or to become secular, given the equilibrium parameters $\rho, \gamma_{R R}, \gamma_{R S}$. Suppose that this individual has an intermediate $q$, and that her best response is to cooperate against fellow religious opponents. We then have:

$$
\begin{aligned}
& V_{R}\left(q^{i}\right)= \\
& \rho\left(\gamma_{R R} d+\left(1-\gamma_{R R}\right) c\right)+(1-\rho) a+\varepsilon \rho\left(1-2 q_{c}^{i}\right)+\varepsilon(1-\rho)\left(1-2 q_{d}^{i}\right) \\
& -\rho\left(\gamma_{R S} b+\left(1-\gamma_{R S}\right) a\right)-(1-\rho) a-\varepsilon\left(1-2 q_{d}^{i}\right)
\end{aligned}
$$

As $q^{i}=q_{c}^{i}-q_{d}^{i}, V_{R}\left(q^{i}\right)$ can be written as:

$$
\begin{aligned}
V_{R}\left(q^{i}\right) & =\rho\left(\gamma_{R R} d+\left(1-\gamma_{R R}\right) c-\gamma_{R S} b-\left(1-\gamma_{R S}\right) a\right)-2 \varepsilon \rho q^{i} \\
& =M\left(q^{i}\right)+S\left(q^{i}\right)
\end{aligned}
$$

where

$$
\begin{aligned}
M\left(q^{i}\right) & =\rho\left(\gamma_{R R} d+\left(1-\gamma_{R R}\right) c-\gamma_{R S} b-\left(1-\gamma_{R S}\right) a\right) \\
S\left(q^{i}\right) & =-2 \varepsilon \rho q^{i}
\end{aligned}
$$

For the religious, there are two reasons for preferring to stay religious. A "material" motivation, $M\left(q^{i}\right)$, arises due to a material gain -as a religious individual may obtain a higher level of cooperation from society if $\gamma_{R R}>\gamma_{R S}$, and a material loss -as a religious individual takes suboptimal actions -cooperates- against fellow religious ones. If she were to be secular 
she would lose the material gain but avoid the material loss from cooperation. The material payoff depends on $q^{i}$ only through its effect on behaviour.

A "spiritual" motivation, $S\left(q^{i}\right)$, arises when religious individuals anticipate that they will cooperate more often when religious, both because of the beliefs instilled by the religion, but also because others might cooperate against them more often. If they become secular on the other hand, they will defect - a scenario they may wish to avoid given their current beliefs. The spiritual payoff depends directly on $q^{i}$ and arises because religious participation has an effect on beliefs in our model.

The above decomposition of the religious type's benefit into a material and spiritual payoff holds more generally for all types $q^{i} \in[-1,0]$. Moreover if we compute the analogous relative benefit of being religious for secular individuals, it would solely consist of the material payoff.

We show in the appendix that all equilibria (with seculars) can be characterized by solving for $q^{\prime}$ at which the benefit of being religious equates the cost of joining the religion,

$$
V_{R}\left(q^{\prime}\right)=r
$$

For example, if the marginal type who joins the religion is, as above, an intermediate type who cooperates against fellow religious agents, the fixed point equation in $q^{\prime}$, given (1), becomes (as $\rho=F\left(q^{\prime}\right), \rho \gamma_{R S}=F(\underline{q})$ and $\gamma_{R R}=1$ ):

$$
\left(F\left(q^{\prime}\right)-F(\underline{q})\right)(d-a)+F(\underline{q})(d-b)-2 \varepsilon q^{\prime} F\left(q^{\prime}\right)=r
$$

We show in the appendix that, for any $F$, and as long as $r$ is not too large, solutions exist to sustain different types of religious organizations, which we describe next.

\subsection{Taxonomy of religious organizations}

Religious organizations are differentiated according to the level of internal as well as external cooperation:

Proposition 2 Any equilibrium with a religious organization is characterized by one of the following configurations, and each such configuration exists for some values of $r$ :

(i) Religions with full cooperation: All (and only) individuals with $q^{i} \leq q^{\prime}$ for some $q^{\prime} \leq \underline{q}$ are religious, and they cooperate with all opponents.

(ii) Religions with selective cooperation: All (and only) individuals with $q^{i} \leq q^{\prime}$ for some $\underline{q}<q^{\prime} \leq \bar{q}$ are religious; religious individuals in $\left[\underline{q}, q^{\prime}\right]$ defect against seculars and cooperate against religious opponents. 
(iii) Religions with free riders: All individuals with $q^{i} \leq q^{\prime}$ for some $\underline{q}<q^{\prime}<\bar{q}$, and in addition some with $q^{i}>q^{\prime}$, are religious. Religious individuals in $\left[\underline{q}, q^{\prime}\right]$ defect against seculars and cooperate against religious opponents, whereas religious in $\left[q^{\prime}, 0\right]$ defect against all.

(iv) Religious societies: All individuals in society are religious; those below $q^{\prime}$ for some $\underline{q} \leq q^{\prime} \leq \bar{q}$, cooperate and those above $q^{\prime}$ defect against all.

In the full cooperation religion, only individuals below $\underline{q}$ are religious. These agents cooperate indiscriminately, so that $\gamma_{R R}=\gamma_{R S}=1$. There is no material benefit from being religious, only a material loss. Still, agents are religious because of the spiritual payoff.

In the selective cooperation religions, religions are larger and its members are less cooperative towards seculars; intermediates cooperate only against their fellow religious opponents so that $1=\gamma_{R R}>\gamma_{R S}$. Such selective behaviour can be found in the scriptures and preaching of several religions and its role seems to be to increase kinship feelings to the larger community. ${ }^{12}$ In these equilibria both a spiritual and a material benefit exist.

In some equilibria "free riders" join the religion and defect against all, so that $\gamma_{R R}<1$. These free riders become religious to take advantage of the material benefit. They can be thought of as non-believers who nonetheless attend church and participate in religious life. Huber (2005) finds empirical evidence that some church goers are non-believers, mainly in less-developed countries that exhibit strong network effects.

Finally, the whole society can be religious. The material benefit is based on the out of equilibrium beliefs that intermediate types defect against seculars. This equilibrium - and only this one - can be sustained for negative values of $r$, i.e., religious rituals can be directly beneficial to one's utility. In all other configurations $r$ has to be strictly positive; otherwise, all types, who when religious defect against fellow members, would be in the religion (as they have a non-negative material benefit from doing so).

\subsection{The secular benefits of religion: a normative result}

Our model has identified the secular benefits of religion; religious individuals enjoy a higher level of cooperation, and moreover, compared with a fully secular society, religion enhances cooperation overall. Such benefits are an important distinction between our paper and previous ones, who emphasized the role of religion as providing spiritual religious goods. Moreover, there are many documented examples of how religions enhance social cohesion and cooperation,

\footnotetext{
${ }^{12}$ For example, in Judaism, "you shall not hate your brother in your heart" (Leviticus 19:17) and "Do not act vengefully or bear a grudge against members of your nation" (Leviticus 19:19) are based on a concept of "national mutuality" and specifically apply to Jews only.
} 
benefiting group members and sometimes non-members through spillovers. ${ }^{13}$ To give one such contemporary example, consider the Korean Christian Church in Houston, Texas. Kwon, Ebaugh and Hagan (1997) provide the following account by one of the members:

\begin{abstract}
"When I came to Houston, I did not know a single person here...I went to a Korean church...Soon, they found me a position in a restaurant which was operated be a church member. He allowed me to eat as much as I wanted...that's how I saved money to start my "road sales" business. I continued to attend the church. Later, when I opened my shop, many church members came to my shop as customers."
\end{abstract}

When we consider whether religion is potentially welfare-improving in society, such benefits are obviously on the positive side. On the other hand, religion might decrease individuals' welfare; members of religious organizations might hold wrong beliefs that will lead them to take suboptimal actions. In addition, religious participation involves costly rituals that might be unproductive or wasteful. ${ }^{14}$ Thus there may be a trade-off between social cohesion on one side and "erroneous beliefs" and costly practice on the other.

Abstracting from the spiritual payoff provided by the religion to its members (which depends on the true distribution governing the shocks), we find that for some parameters, the material benefits of religion can be large enough so that the existence of religion is Pareto-improving:

Proposition 3 For some parameters, an equilibrium with religion provides all individuals in society a higher material utility than when everyone is secular.

The material benefit gained by enhanced internal cooperation within the religion, is sometimes large enough to outweigh the cost of rituals as well as the suboptimal actions taken by some religious individuals against seculars (namely, that they cooperate). Moreover, the seculars in society benefit from the spillovers in social cohesion that arise with such organizations. Thus, religion can be welfare-improving to all.

\title{
3.4 Intensity of rituals and the size of religion: a monotonicity result
}

Religious organizations differ in the level of cooperation they induce, their size, and their intensity of rituals. When the level of the shock is large enough, we find a monotone relationship

\footnotetext{
${ }^{13}$ Wilson (2002) discusses several cases of historical and contemporary religions which provide "secular utility" to its members.

${ }^{14}$ The Anthropology literature provides many examples of intense ritualistic societies. One extreme example discussed in Boyer (2001) are some religions in Melanesia where people perform an extraordinary number of rituals to protect themselves from witchcraft.
} 
among these parameters. Namely, a higher intensity of rituals is associated with a smaller religion and a larger degree of internal and external cooperation:

Proposition 4 For sufficiently high values of $\varepsilon$, there exist values $\bar{r}>r^{1}>r^{2}>\underline{r}>0$ such that:

(i) For any $r \in[0, \bar{r}]$ there exists a unique equilibrium with religion.

(ii) For any $r \in\left[r^{1}, \bar{r}\right]$ the religion has full cooperation, for any $r \in\left[r^{2}, r^{1}\right]$ the religion has selective cooperation, for any $r \in\left[\underline{r}, r^{2}\right]$ the religion has free riders and for any $r \leq r^{2}$, society is fully religious.

(iii) For all $r \leq \bar{r}$, religious membership ( $\rho$ ) decreases in the intensity of rituals $(r)$, whereas internal and external cooperation $\left(\gamma_{R R}\right.$ and $\left.\gamma_{R S}\right)$ increase in $r$.

The intuition for the monotonicity result relies on the two motivations for being religious. By the material motivation, the cost of religion should increase when the religion is larger as then more intermediate types, who cooperate selectively and provide these relative benefits, are religious. On the other hand, by the spiritual motivation, the cost of religion should decrease when more intermediate types are religious, as the marginal type is less averse to defection. When the shocks are large enough, the spiritual motivation dominates, inducing a negative monotone relationship between the cost of religion and its size.

Several empirical studies support this monotone relationship; Iannaccone (1992) finds that the stricter is the church in its demands, the higher is the level of contributions (in money and time) within the church. Within religions, Iannaccone (1998) finds that more conservative denominations have members who contribute proportionally more income, attend more services, and have more orthodox doctrinal beliefs. In an experimental study in Israeli Jewish Kibbutzim, Sosis and Ruffle (2003) find that religious males are more cooperative compared with seculars and with religious females (who participate in fewer rituals), and that cooperation increases with synagogue attendance.

\subsection{Secularization and economic development: comparative statics results}

We conclude our main section with a comparative statics analysis of the implications of scientific progress and economic development on religious organizations. Weber (1904 and 1922) advanced the secularization hypothesis claiming that as science progresses, the role that religion has to play in people's life, re-assuring and explaining the world around them, will diminish. Durkheim (1912) reached a similar conclusion, that the role of religion will diminish over time, but for an institutional reason: economic and state development will crowd out the 
social institutions of the religion. ${ }^{15}$

As more and more scientific knowledge becomes available it might make individuals less prone to be affected by religious preaching. Thus, we can capture the effects of scientific progress by a shift in $F$, in a first order stochastic sense. In the limit, when no types with low values of $q$ (less than $\bar{q}$ ) exist in society, a religious organization cannot arise.

Economic development implies that individuals can insure themselves against stochastic welfare shocks. To analyze an increase in economic development we consider a decrease in the value of $\varepsilon$. In the limit, when shocks are negligible compared to the outcomes of the PD, a religious organization will not arise.

While the above arguments suggest a simple relation between modernization and religious participation, our model suggests a more complex one. To asses this, it is sufficient to analyze the incentives of the marginal religious type. ${ }^{16}$ Consider such type in a religious organization with selective cooperation. The marginal type, $q^{\prime}$ is determined by,

$$
\left(F\left(q^{\prime}\right)-F(\underline{q})\right)(d-a)+F(\underline{q})(d-b)-2 \varepsilon q^{\prime} F\left(q^{\prime}\right)=r
$$

Suppose we change the distribution of types in society from $F$ to $F^{\prime}$ where $F^{\prime}$ first order stochastically dominates $F$. The first expression represents a material gain from being religious as a share of the religious, namely $F\left(q^{\prime}\right)-F(\underline{q})$, cooperates only when their opponent is religious. A shift to $F^{\prime}\left(q^{\prime}\right)-F^{\prime}(\underline{q})$ can increase or decrease this term so to fix ideas suppose that $F^{\prime}\left(q^{\prime}\right)-F^{\prime}(\underline{q})=F\left(q^{\prime}\right)-F(\underline{q})$. The second expression represents a material loss; a religious $q^{\prime}$ cooperates against agents with $q<\underline{q}$, whereas if he were to be secular, he could take advantage of them by defecting. The magnitude of this loss depends on $F(\underline{q})$ so a shift to $F^{\prime}(\underline{q})<F(\underline{q})$ reduces this loss. Finally, the spiritual benefit depends on total religious participation, $F\left(q^{\prime}\right)$, as this corresponds to the likelihood that the agent will cooperate. A shift to $F^{\prime}\left(q^{\prime}\right)<F\left(q^{\prime}\right)$ decreases therefore the spiritual gain.

Thus, the spiritual and material motivations are at odds, which renders the effect of scientific progress on religious participation ambiguous. On the other hand, an increase in economic development -a decrease in $\varepsilon$ - decreases religious participation unambiguously. More generally, in some other equilibria, we establish a clear relationship between scientific and economic development on religious participation:

\footnotetext{
${ }^{15}$ The evidence on secularization is mixed. For a summary of the empirical evidence on secularization, see Huber (2005).

${ }^{16}$ In the proof of Proposition 4 we show that for relatively high levels of shocks the benefit of being religious is monotone and thus the change in benefit for the marginal type translates, one-to-one, to the effect on religious participation in the new equilibrium.
} 
Proposition 5 For sufficiently high values of $\varepsilon$ :

(i) An increase in economic development decreases the size of the full cooperation religion, selective cooperation religion and for some parameters, the religion with free riders.

(ii) An increase in scientific knowledge decreases the size of the full cooperation religion but has an ambiguous effect on other religions.

\section{Religious groups and competition for members}

In the first extension of our model, we consider the different ways in which competition between religious groups manifests itself. We first allow for several religious groups to emerge and examine the patterns of cooperation between them. We then assume that group members can partake in explicit hostile activities against non-affiliated ones; we show that such conflicts may arise as a tool to increase the group membership.

\subsection{Hierarchies of religions}

Iannaccone (1994) finds that "Relative to their more mainstream counterparts, members of sectarian groups-both Christian and Jewish- hold fewer memberships in outside groups, contribute less to outside causes, and have fewer outside friends." Farber (2001) shows how Orthodox Jews have been actively hostile towards the less demanding movements, conservative and reform Judaism. These studies indicate that the stricter denominations might be less cooperative towards other ones.

We now extend the model to allow for more than one religious group, in order to explore such asymmetric relations between denominations. For simplicity, we assume that an agent's type $q^{i}$ determines his beliefs in any religious affiliation so that all religions face the same $F$ in society. ${ }^{17}$

We say that a religious group is "tolerant" ("intolerant") towards another religious group if the (some) members of the group who cooperate internally, cooperate (defect) when matched with members of the other group. The next result illustrates that whether groups are tolerant towards one another depends on their internal level of cohesiveness,

Proposition 6 (i) Whenever there is non-tolerance between a full cooperation group and another religious group, then the full cooperation group must be non-tolerant. (ii) For some parameters, there exists an equilibrium with one tolerant selective cooperation group and one

\footnotetext{
${ }^{17}$ Our results do not rely on this assumption; given the assumption it is straightforward to extend the equilibrium notion presented in Section 2 to several groups.
} 
intolerant full cooperation group, in which the full cooperation group has a higher intensity of rituals.

Our result implies a hierarchy of churches or denominations - the stricter church, with the higher intensity of rituals, is less cooperative towards other churches or religions who are less strict in their demands.

\subsection{Conflicts and hostility}

So far we have interpreted group intolerance as the discriminating behaviour of these group members towards non affiliated members. But intolerance, hostility, or conflicts in society are often more centrally organized and involve extra curricular activities on top of such daily interactions. We now show how hostile activities may arise in our model. To simplify, we consider such hostile actions in the context of one organized religious group, as in our basic model, and its relation vis a vis seculars.

The religious in our model already participate in some costly activities, namely rituals. These are done in the social domain and can include praying or ceremonies. One way to think about hostile activities is to embed them within the rituals; the costly observable actions that both identify members with the religion and signal their beliefs may include participation in demonstrations, or violent activities that hurt non-members.

We therefore add a parameter $v$ so that $r=r^{\prime}+v$, where $v$ affects the utility of a secular individual in a negative way, inflicting a cost $c(v, \rho)>0$ increasing in both elements. This implies that the relative cost of joining the religion is now $r-c(v, \rho)$. As the effective cost of religious participation decreases, by the monotonicity result of Proposition 4, religious participation will in turn increase:

Corollary 1: For sufficiently high values of $\varepsilon$, an increase in $v$ increases the size of the religion.

The implication of the corollary is that groups that can impose costly actions on others, have an incentive to do so. If religious leaders put weight on participation and if the technology of violence, $c(v, \rho)$, is relatively efficient, they have an incentive to instruct members to inflict some cost on non-members. In that sense, competition for members between religious and secular groups or more generally between several religious groups can lead simultaneously to a higher religious participation and more violence in society. 


\section{The dynamics of religion}

Personal experiences are important in shaping individuals' attitudes and beliefs towards religion, and are often mentioned as motivations for conversions or deconversions. ${ }^{18}$ We now analyze how realized shocks to the well being of individuals affect their beliefs and what it implies for the dynamics of religious organizations. We first consider how correlated shocks to the whole population affect religious participation in the short term, and then discuss the long term survival of religious organizations.

To allow for belief dynamics, assume that each individual does not know the exact values of $q_{c}^{i}$ and $q_{d}^{i}$ but rather his type is such that $q_{c}^{i}$ and $q_{d}^{i}$ are taken (independently) from fullsupport density functions $f^{i}\left(q_{c}^{i}\right)$ and $f^{i}\left(q_{d}^{i}\right)$, respectively. The definition of $q^{i}$ is now altered to $q^{i}=E^{i}\left(q_{c}^{i}\right)-E^{i}\left(q_{d}^{i}\right)$. We fix the initial types in the population $-f^{i}\left(q_{c}^{i}\right)$ and $\left.f^{i}\left(q_{d}^{i}\right)\right)$ - and let each individual update his type following his course of play, and the shock he receives. ${ }^{19}$

The following Lemma will be useful for our analysis; it establishes that in response to a shock, individuals update their beliefs conditional on the action they have played in the game: ${ }^{20}$

Lemma 1 (i) Following a negative shock, an agent who cooperated (defected) will decrease (increase) his $q^{i}$. (ii) Following a positive shock, an agent who cooperated (defected) will decrease (increase) his $q^{i}$.

Intuitively, an individual who has been cooperating and experienced a positive shock, believes that on average $q_{c}^{i}$ is lower but does not change his beliefs on $q_{d}^{i}$, whereas an individual who has been defecting and experienced a positive shock, believes that on average $q_{d}^{i}$ is lower and does not change his beliefs on $q_{c}^{i}$. Similar intuition holds for negative shocks. An implication of Lemma 1 is that individuals will update their beliefs depending on the particular equilibrium they play, as this determines the actions they take in the PD game.

\subsection{Religion in "good" and "bad" times}

Following natural and other disasters, individuals and religious leaders often re-evaluate, or feel a need to justify, their religious stances (e.g., Jewish theology after the holocaust). Recent empirical work (Chen (2008)) suggests that following the financial crisis in Indonesia, religious

\footnotetext{
${ }^{18}$ For example, the 1966 Nobel laureate in Literature, S.Y. Agnon, became religious after in 1924 he lost five years worth of writings in a fire.

${ }^{19}$ We assume that individuals do not learn from the observation of others' actions and shocks; this could be motivated by imperfect observability of others' actions or experiences.

${ }^{20}$ This is a similar effect to the one in Piketty (1995).
} 
participation had increased. We now discuss how correlated shocks to the whole of society affect religious participation. ${ }^{21}$ We illustrate such dynamics by focusing on the selective cooperation equilibrium.

Suppose first that all individuals in society experience a positive shock (e.g., an economic boom). By Lemma 1, all individuals with relatively low $q^{i}$, who have been cooperating, will decrease their $q^{i}$ even further, and all those with relatively high $q^{i}$, who have been defecting, will increase their $q^{i}$ even further. However, some religious individuals with intermediate $q^{i}$, who have been defecting, will increase their $q^{i}$, possibly enough to switch affiliation to seculars. Thus, a correlated positive shock will tend to both polarize beliefs in society and decrease the size of the religion.

On the other hand, a negative shock (e.g., a natural disaster) will have the opposite effect in terms of beliefs. Agents with relatively high $q^{i}$ who have been defecting will reduce their $q^{i}$ (and might become religious) while agents with low $q^{i}$ who have been cooperating will increase their $q^{i}$ (and might become seculars). The effect of a correlated negative shock on religious participation is therefore ambiguous. Everything else equal, the size of the religion will increase following a negative shock, if the religion is small enough to start with. To see why, note that the smaller is the religion, the less likely it is that intermediate religious types cooperate and are thus less likely to leave the faith. On the other hand, seculars defect against whoever they meet so that the inflow rate to the religion is not affected by its original size.

\subsection{Maintaining religious beliefs}

Church (as well as religious ceremonies) attendance in Britain have been steadily falling from around $40 \%$ in 1850 to $10 \%$ in 1990's, whereas in the U.S. it remained flat during these times. Similarly, while some religious groups show strong persistence through time, some systems of beliefs and practices have vanished. Which religious organizations will survive in the long run - if at all?

In Section 4.1. we illustrated how religious organizations affect the distribution of beliefs in society whereas our basic model had determined how the distribution of beliefs affects the form of religious organizations. We can now use this reciprocal relationship between beliefs and religious organizations to analyze whether religions can be sustained in the long term.

To make the survival of religion more difficult, assume that there is no relation between

\footnotetext{
${ }^{21}$ Recall that the beliefs we consider are only about the relation between individuals' actions and their personal shocks. Thus, individuals cannot interpret a common shock as the result of a communal sin. This assumption does not affect the qualitative nature of our results but does affect their magnitude.
} 
social actions and shocks (so that the truth is "secular"). Nonetheless, beliefs that induce individuals to cooperate against all opponents will allow them to maintain erroneous beliefs about the relative benefit of defecting; such types may stick to their beliefs forever as they do not learn anything about defection. ${ }^{22}$ Thus, the full cooperation equilibrium can be sustained in the long run in some environments, even when the truth is "secular". ${ }^{23}$

On the other hand, in the selective cooperation (or free riding) equilibria, intermediate types experiment, i.e., they sometimes cooperate and sometimes defect. As they learn about all possible actions, in the long run, they (or their offsprings) will converge to hold beliefs which are close to the truth. Thus, no intermediate types can exist in the long run. In other words, religions with selective cooperation, or with free riders, cannot survive.

We can conclude that such organizations -that include some selective cooperation- can potentially survive only if beliefs are immune to available information. However, several religious practices can allow religions (or religious leaders) to do exactly that: either censor information or create systems of beliefs that are immune to it. Our model can therefore shed light on such practices:

\section{The "Afterlife"}

Focusing beliefs on rewards and punishment in the afterlife implies that such beliefs are not verifiable in this life. Indeed, the Judeo-Christian traditions, bring the afterlife, with its concepts of heaven and hell, to the fore. Similarly, the Eastern religions such as Hinduism, Buddhism and Sikhism, share beliefs of reincarnation, in which the future "self" will pay for the sins or gain from the good deeds of the current one. Some religious writings however are based only on this life. ${ }^{24}$

\section{Forgiveness}

Forgiveness, with its twin concepts of atonement and repent, are important concepts in the Judeo-Christian tradition. While there are different explanations to the usefulness of forgiveness and its function in religious organizations, our model suggests another way to view this religious practice. In some sense, forgiveness blurs the relation between actions and rewards. While an omnipresent God will surely know that one has sinned, it is not known

\footnotetext{
${ }^{22}$ Their beliefs about cooperation $\left(q_{c}^{i}\right)$ will converge to the truth and will be "self-confirming", as in Fudenberg and Levine (1993).

${ }^{23}$ The equilibrium in which all individuals in society are religious may exist in the long run as well. In both this and the full cooperation equilibria individuals always cooperate or always defect disregarding their opponent affiliation.

${ }^{24}$ Such as the Nuer (in Evans-Pritchard 1956) or ancient Germanic religions.
} 
whether God has forgiven or not, and hence whether punishment will be inflicted upon the individual.

\section{Complicated systems of beliefs}

Our analysis is simplified by the assumption that the shocks depend only on individual actions; it is often believed that the whole collective is punished for the sins of some, or escapes punishment due to the good deeds of others. Such more complicated systems of religious beliefs make it harder for individuals to update their beliefs correctly. First, the behaviour of others is often not observed and hence cannot be conditioned upon. Second, even if the behaviour of one's opponent is observed, equilibrium observations of play will not constitute sufficient information as typically they will not include all possible configurations of actions. Thus, full learning will not arise in the long run.

\section{Segregation}

Many religious organizations tend to segregate their members from non-members either physically or in other ways that limit access to information about the experiences of nonmembers. ${ }^{25}$ The benefit of such segregation can be two-fold. First, religious agents will mostly meet other religious agents and will avoid being taken advantage of. A second benefit is that such isolation might allow the religious to avoid information that is unfavorable for the prevalence of their beliefs.

\section{Conclusion}

We have proposed a simple model of religious organizations which relies on the ability of such organizations to affect beliefs of individuals about the relation between their social actions and shocks to their utility. The model ties together the three most observed aspects of religious organizations: beliefs, social behaviour, and rituals.

We have analyzed the stability of religious organizations and their features, but abstracted away from how they arise; the role of religious leaders as selecting these organizations is an important extension which we leave for future research. Another related topic is "religious governance", i.e., the study of the structure of religious organizations. While some religions are centralized (e.g., the Roman Catholic church), others (such as Islam) are decentralized. Such differences may depend on features -some related to our model- such as the importance

\footnotetext{
${ }^{25}$ An extension of our model in which individuals who belong to the same affiliation can be matched to play the PD game with members from this affiliation only yields qualitatively similar results.
} 
of network effects, the level of competition for members, or the importance of church-state links. 


\section{References}

[1] Barro, R. and R. McCleary (2003), "Religion and Economic Growth", mimeo, Harvard.

[2] Benabou, R. and J. Tirole (2006), "Belief in a Just World and Redistributive Politics," Quarterly Journal of Economics, vol. 121(2), pp. 699-746.

[3] Berman, E. , (2000), "Sect, Subsidy and Sacrifice: An Economist's View of Ultra-Orthodox Jews", Quarterly Journal of Economics, vol. 115(3), pp. 905-953.

[4] Bisin, A. and T. Verdier (2001), "The Economics of Cultural Transmission and the Evolution of Preferences", Journal of Economic Theory, vol. 97(2), pp. 298-319.

[5] Boyer, P. (2001), Religion Explained, Basic Books, New York, NY.

[6] Bradley , E. (1995), "Religious Involvement and Social Resources: Evidence from the Data Set "Americans' Changing Lives", Journal for the Scientific Study of Religion 34(2), 259-267.

[7] Chen, D. (2008), "Club Goods and Group Identity: Evidence from Islamic Resurgence During the Indonesian Financial Crisis", mimeo, Harvard.

[8] Durkheim, Émile. 1912. The Elementary Forms of Religious Life. New York: The Free Press.

[9] Evans-Pritchard, E.E (1956), Nuer Religion, Clarendon press, Oxford.

[10] Ellison, C. G., and L. K. George (1994), "Religious Involvement, Social Ties, and Social Support in a Southeastern Community", Journal for the Scientific Study of Religion, vol. 33, pp. 46-61.

[11] Farber, S. (2001), "Reproach, Recognition and Respect: Rabbi Joseph B. Soloveitchik and Orthodoxy's Mid-Century Attitude Toward Non-Orthodox Denominations", American Jewish History 89, pp. 193-214

[12] Fudenberg, D. and D. K. Levine (1993), "Self-confirming Equilibrium", Econometrica 61, pp. 523-545.

[13] Gruber, J. (2003), "Religious Market Structure, Religious Participation, and Outcomes: Is Religion Good for You?", mimeo, MIT. 
[14] Guiso, L. P. Sapienza and L. Zingales (2003), "People's Opium? Religion and Economic Attitudes", Journal of Monetary Economics, vol. 50, pp. 225-282.

[15] Huber, J.D. (2005), "Religious belief, religious participation, and social policy attitudes across countries", working paper, Columbia University.

[16] Iannaccone, L. (1992), "sacrifice and stigma: reducing free-riding in cults, communes and other collectives", Journal of Political Economy, vol. 100(2), pp. 271-291.

[17] Iannaccone, L. (1994), "Why strict churches are strong", American Journal of Sociology 95, pp. 1180-1211.

[18] Iannaccone, L. (1998), "Introduction to the Economics of Religion," Journal of Economic Literature, vol. 36(3), pp. 1465-1495.

[19] Kwon, H., H. R. Ebaugh, and J. Hagan (1997), "The Structure and Functions of Cell Group Ministry in an American Korean Church." Journal for the Scientific Study of Religion, vol. 36 (2): 247-256.

[20] Orbell, J. M., M. M. Goldman, and R. Dawes (1992), "Religion, context, and constraint toward strangers", Rationality and Society, vol. 4(3), pp. 291-307.

[21] Piketty, T. (1995), "Social mobility and redistributive politics", Quarterly Journal of Economics, vol. 110(3), pp. 551-584.

[22] Sosis, R. and B.J. Ruffle (2003) "Religious Ritual and Cooperation: Testing for a Relationship on Israeli Religious and Secular Kibbutzim", Current Anthropology, vol. 44(5), pp. $713-722$.

[23] Stark, R. (1996), The Rise of Christianity, Princeton University Press, Princeton.

[24] Stasavage, D. and K. Scheve (2006), "Religion and Preferences for Social Insurance", Quarterly Journal of Political Science, vol.1, pp.255-286s.

[25] Tabellini, G. (2007), "The Scope of Cooperation: Values and Incentives", mimeo.

[26] Weber, Max. 1904. The Protestant Ethic and the Spirit of Capitalism. New York: Scribners (translated by T. Parsons, 1930).

[27] Weber, Max. 1922. The Sociology of Religion. Boston: Beacon.

[28] Wilson, D.S. (2002), Darwin's Cathedral, University of Chicago Press, Chicago. 


\section{APPENDIX}

Proof of Proposition 1 And 2: Recall that secular individuals always defect, religious individuals below $\underline{q}$ always cooperate, religious individuals above $\bar{q}$ always defect, and intermediates defect against seculars. It is therefore left to consider how intermediates behave against fellow religious members. A religious individual will defect against another religious agent, who cooperates with probability $\gamma_{R R}$, if:

$$
\gamma_{R R} b+\left(1-\gamma_{R R}\right) a+\varepsilon\left(1-2 q_{d}^{i}\right) \geq \gamma_{R R} d+\left(1-\gamma_{R R}\right) c+\varepsilon\left(1-2 q_{c}^{i}\right)
$$

or when $q^{i} \geq q_{R R}$, for

$$
q_{R R} \equiv \frac{1}{2 \varepsilon}\left((d-b) \gamma_{R R}+(c-a)\left(1-\gamma_{R R}\right)\right)=\gamma_{R R} \bar{q}+\left(1-\gamma_{R R}\right) \underline{q}
$$

where $q_{R R}$ and $\gamma_{R R}$ are endogenously determined in equilibrium.

We first consider the relative benefit of a religious agent from being religious vs. being secular:

Lemma A1 For a religious agent, the relative benefit of being religious is monotonically decreasing and continuous in $q^{i}$.

Proof: For a type below $\underline{q}$, the relative benefit of being religious is given by:

$$
\begin{aligned}
& \rho\left(\gamma_{R R} d+\left(1-\gamma_{R R}\right) c\right)+(1-\rho) c+\varepsilon\left(1-2 q_{c}^{i}\right) \\
& -\rho\left(\gamma_{R S} b+\left(1-\gamma_{R S}\right) a\right)-(1-\rho) a-\varepsilon\left(1-2 q_{d}^{i}\right) \\
= & M^{q^{i} \leq \underline{q}}\left(\rho, \gamma_{R R}, \gamma_{R S}\right)-2 \varepsilon q^{i},
\end{aligned}
$$

where $M^{q^{i} \leq \underline{q}}\left(\rho, \gamma_{R R}, \gamma_{R S}\right)$ is fixed for all $q^{i} \leq \underline{q}$ and represents "material" payoffs from the $\mathrm{PD}$ game, while the second term above, $-2 \varepsilon q^{i}$, represents the "spiritual" payoff.

For types above $\underline{q}$ and below $q_{R R}$, the relative benefit for being religious is given by:

$$
\begin{aligned}
& \rho\left(\gamma_{R R} d+\left(1-\gamma_{R R}\right) c\right)+(1-\rho) a+\varepsilon \rho\left(1-2 q_{c}^{i}\right)+\varepsilon(1-\rho)\left(1-2 q_{d}^{i}\right) \\
& -\rho\left(\gamma_{R S} b+\left(1-\gamma_{R S}\right) a\right)-(1-\rho) a-\varepsilon\left(1-2 q_{d}^{i}\right) \\
= & M^{q} \leq q^{i} \leq q_{R R}\left(\rho, \gamma_{R R}, \gamma_{R S}\right)-2 \varepsilon \rho q^{i} .
\end{aligned}
$$

Where again the material benefit is fixed for these types and does not change with $q^{i}$. It is different though from the material benefit for the lower types as these types defect more often. Finally for types above $q_{R R}$ :

$$
\begin{aligned}
& \rho\left(\gamma_{R R} b+\left(1-\gamma_{R R}\right) a\right)+(1-\rho) a+\varepsilon\left(1-2 q_{d}^{i}\right) \\
& -\rho\left(\gamma_{R S} b+\left(1-\gamma_{R S}\right) a\right)-(1-\rho) a-\varepsilon\left(1-2 q_{d}^{i}\right) \\
= & M^{q_{i}>q_{R R}}\left(\rho, \gamma_{R R}, \gamma_{R S}\right)=\rho\left(\gamma_{R R}-\gamma_{R S}\right)(b-a) \geq 0 .
\end{aligned}
$$


Moreover, one can show that $M^{q^{i} \leq \underline{q}}\left(\rho, \gamma_{R R}, \gamma_{R S}\right)-2 \varepsilon \underline{q}=M^{q} \leq q^{i} \leq q_{R R}\left(\rho, \gamma_{R R}, \gamma_{R S}\right)-2 \varepsilon \rho \underline{q}$ and that $M^{q} \leq q^{i} \leq q_{R R}\left(\rho, \gamma_{R R}, \gamma_{R S}\right)-2 \varepsilon \rho q_{R R}=M^{q_{i}>q_{R R}}$, hence the benefit is continuous in $q^{i}$. $\square$

Given the monotonicity property in Lemma A1, and given some $r, \rho, \gamma_{R S}$ and $\gamma_{R R}$, it is optimal for all religious agents below some $q^{\prime}$ to be religious.

The expressions for the material payoffs above represent the relative benefit of being religious as viewed by the seculars, as these agents consider only the material payoff when evaluating affiliation choices:

Lemma A2 (i) For seculars, the relative benefit from being religious is (weakly) monotonically increasing in their type $q^{i}$. (ii) The relative benefit from being religious is equal for a secular type and for a religious type above $q_{R R}$.

If $q^{\prime}$ is high enough such that a religious agents above $q_{R R}$ strictly prefers to be religious, then, together with condition (iii) of the equilibrium definition, all society is religious in equilibrium. If on the other hand $q^{\prime}$ is low enough so that such a religious type prefers to be secular, then by Lemma A2, such a secular type also prefers to stay secular, and also all other secular types prefer to stay secular. Thus, all secular agents with $q \geq q^{\prime}$ will, at least weakly, prefer to be secular. This insures that no secular individual will prefer to be religious and no religious individual will prefer to be secular. Together with condition (iii), we can then look for equilibria in which all agents with types below $q^{\prime}$ are religious. Thus there could only be four types of equilibria, depending on the level at which $r$ intersects the religious benefit function outlined in Lemma A1 above:

\section{Full cooperation religion}

In the first family of equilibria, $1=\gamma_{R R}=\gamma_{R S}>0$, and members are only below $\underline{q}$. Also, $q_{R R}=\bar{q}$. Let $r_{1}=2 \varepsilon F(\underline{q})(\bar{q}-\underline{q})$ and $r_{2}=2 \varepsilon(\underline{q}+1)$. Note that $\min \left\{r_{1}, r_{2}\right\}>0$. We now show that these equilibria hold for any $r \in\left[\min \left\{r_{1}, r_{2}\right\}, \max \left\{r_{1}, r_{2}\right\}\right]$.

What we need to determine is the marginal type, who is indifferent between being religious and being secular, given his beliefs $q^{\prime}$. We therefore need to solve:

$$
\begin{aligned}
M^{q_{i} \leq \underline{q}}\left(\rho, \gamma_{R R}, \gamma_{R S}\right)-2 \varepsilon q^{\prime} & =r \Leftrightarrow \\
F\left(q^{\prime}\right)(d-b)+\left(1-F\left(q^{\prime}\right)\right)(c-a)-2 \varepsilon q^{\prime} & =r \Leftrightarrow \\
F\left(q^{\prime}\right) \bar{q}+\left(1-F\left(q^{\prime}\right)\right) \underline{q}-q^{\prime} & =\frac{r}{2 \varepsilon}
\end{aligned}
$$

To see why a solution exists to the above fixed point equation in $q^{\prime}$, consider some $r$ in the range described above. If $q^{\prime}=-1$, then, as $F\left(q^{\prime}\right)=0$, we have that the left-hand-side of the equation is $\underline{q}+1$ which is greater (smaller) than the right-hand-side when $r_{1}<r_{2}\left(r_{1}>r_{2}\right)$. 
If on the other hand, $q^{\prime}=\underline{q}$, then the left-hand-side becomes $F(\underline{q})(\bar{q}-\underline{q})$, and it is smaller (greater) than the right-hand-side when $r_{1}<r_{2}\left(r_{1}>r_{2}\right)$. By continuity, a fixed point exists.

\section{Selective cooperation equilibrium}

In the second type of equilibrium, $1=\gamma_{R R}>\gamma_{R S}>0$. Let $r_{1}=(F(\bar{q})-F(\underline{q}))(b-a)$ and $r_{2}=2 \varepsilon F(\underline{q})(\bar{q}-\underline{q})$. Note that $\min \left\{r_{1}, r_{2}\right\}>0$. We now show that these equilibria hold for any $r \in\left[\min \left\{r_{1}, r_{2}\right\}, \max \left\{r_{1}, r_{2}\right\}\right]$.

Again, as $\gamma_{R R}=1$, we have that $q_{R R}=\bar{q}$. We need to determine which of the types below $q_{R R}$ is the marginal type, i.e., to solve:

$$
\begin{aligned}
& M^{q} \leq q^{i} \leq q_{R R}\left(\rho, \gamma_{R R}, \gamma_{R S}\right)-2 \varepsilon \rho q^{\prime}=r \Leftrightarrow \\
& F\left(q^{\prime}\right)(d-a)-F(\underline{q})(b-a)-2 \varepsilon F\left(q^{\prime}\right) q^{\prime}=r
\end{aligned}
$$

The existence of a fixed point, for the relevant range of $r$, follows from the same argument as described in the previous section with $\underline{q}$ and $\bar{q}$ as the end points.

\section{Free riders equilibrium}

In this family of equilibria, all below $q_{R R}$ and a measure $\alpha$ of types above it are religious, so that $1>\gamma_{R R}>\gamma_{R S}>0$. In response to the introduction of religious types who defect, there are fewer types below $q_{R R}$ so that $q_{R R}<\bar{q}$. Such an equilibrium exists for any $r \in$ $\left[r^{*},(F(\bar{q})-F(\underline{q}))(b-a)\right]$, for some $r^{*}$ that will be defined below.

The equilibrium is a solution to the fixed point equation in (2), where $\gamma_{R R}=\frac{F\left(q_{R R}\right)}{F\left(q_{R R}\right)+\alpha}$. Moreover, as the relative benefit to religious types who defect from being religious does not depend on $q^{i}$, they must be indifferent so that some of them, but not all, are religious. Thus, given the solution to $q_{R R}$, we have to find $\gamma_{R R}$ so that these types are indifferent. For consistency, we let $q_{R R}=q^{\prime}$ :

$$
\begin{aligned}
q^{\prime} & =\frac{F\left(q^{\prime}\right)}{F\left(q^{\prime}\right)+\alpha} \bar{q}+\left(1-\frac{F\left(q^{\prime}\right)}{F\left(q^{\prime}\right)+\alpha}\right) \underline{q} \\
r & =\left(F\left(q^{\prime}\right)-F(\underline{q})\right)(b-a)
\end{aligned}
$$

When $\alpha=0, q^{\prime}$ is set at $\bar{q}$, and is the limit of the selective cooperation equilibria, when there are no "free riders". When $\alpha$ is higher, and the religion has a larger share of free riders, $q^{\prime}$ decreases. To determine the lower bound $\underline{r}$ we can find the limit of these equilibria when the whole population is religious (so that $\rho=1$ ). Specifically, let $\alpha=1-F\left(q^{\prime}\right)$. We then have $r^{*}=\left(F\left(q^{*}\right)-F(\underline{q})\right)(b-a)$ where $q^{*}$ is the solution to $q^{\prime}=F\left(q^{\prime}\right) \bar{q}+\left(1-F\left(q^{\prime}\right)\right) \underline{q}$. Note that $r^{*}>0$ as for any full-support distribution function $F, q^{*}>\underline{q}$.

\section{Society with no seculars}


Finally, for any $r \leq r^{*}$, there exists an equilibrium in which the whole society is religious. This equilibrium is as the limit equilibrium described above, which holds for $r^{*}$. In this equilibrium, all agents below $q^{*}$ cooperate, and all agents above $q^{*}$ defect. If an agent deviates and becomes secular, then a share $F\left(q^{*}\right)-F(\underline{q})$ of the population will defect against him. Obviously, this equilibrium can be sustained for any $r \leq r^{*}$, including negative values of $r$.

Proof of Proposition 4: We first show that for high enough $\varepsilon$, the religions specified in Proposition 2 are segregated in $r$ as stated in (ii). In particular, this holds if:

$$
(F(\bar{q})-F(\underline{q}))(b-a)<2 \varepsilon F(\underline{q})(\bar{q}-\underline{q})<2 \varepsilon(\underline{q}+1) .
$$

We now show why (3) holds when $\varepsilon$ is high enough. Consider first the left-hand-side inequality:

$$
\begin{aligned}
(F(\bar{q})-F(\underline{q}))(b-a) & <2 \varepsilon F(\underline{q})(\bar{q}-\underline{q}) \Leftrightarrow \\
(F(\bar{q})-F(\underline{q}))(b-a) & <F(\underline{q})(d-c-(b-a)) \Leftrightarrow \\
\frac{F(\bar{q})}{F(\underline{q})} & <\frac{d-c}{b-a}
\end{aligned}
$$

By strategic complements, $\frac{d-c}{b-a}>1$. On the other hand, the left-hand-side approaches 1 when $\varepsilon$ increases. Consider now the right-hand-side inequality:

$$
\begin{aligned}
2 \varepsilon F(\underline{q})(\bar{q}-\underline{q}) & <2 \varepsilon(\underline{q}+1) \Leftrightarrow \\
F(\underline{q})(\bar{q}-\underline{q}) & <\underline{q}+1
\end{aligned}
$$

When $\varepsilon$ increases the left-hand-side approaches zero whereas the right-hand-side is positive and bounded away from zero.

We now conduct the local analysis which also shows uniqueness. In the full cooperation religion, the equilibrium condition is,

$$
F\left(q^{\prime}\right) \bar{q}+\left(1-F\left(q^{\prime}\right)\right) \underline{q}-q^{\prime}=\frac{r}{2 \varepsilon}
$$

First note that for high enough shocks, as $(\bar{q}-\underline{q})$ becomes arbitrarily small, the left hand side is decreasing in $q^{\prime}$,

$$
\frac{\partial\left(F\left(q^{\prime}\right) \bar{q}+\left(1-F\left(q^{\prime}\right)\right) \underline{q}-q^{\prime}\right)}{\partial q^{\prime}}=\left(\left(f\left(q^{\prime}\right)(\bar{q}-\underline{q})-1\right)\right) .
$$

Total differentiation of the equilibrium condition implies,

$$
\frac{d q}{d r}=\frac{1}{2 \varepsilon\left(\left(f\left(q^{\prime}\right)(\bar{q}-\underline{q})-1\right)\right)}
$$


and as shocks grow large we have,

$$
\frac{d q}{d r}<0
$$

Note that in this equilibrium $\rho=F\left(q^{\prime}\right)$ and so is decreasing in $r$. As for this equilibrium $\gamma_{R S}=\gamma_{R R}=1$, these are weakly increasing in $r$.

In the second type of equilibrium, we have a religion where some of its members cooperate selectively. The equilibrium condition is,

$$
F\left(q^{\prime}\right)(d-a)-F(\underline{q})(b-a)-2 \varepsilon F\left(q^{\prime}\right) q^{\prime}=r
$$

First note that for high enough shocks, the left hand side is decreasing in $q^{\prime}$. The derivative of the left hand side is given by,

$$
\frac{\partial\left(F\left(q^{\prime}\right)(d-a)-F(\underline{q})(b-a)-2 \varepsilon F\left(q^{\prime}\right) q^{\prime}\right)}{\partial q^{\prime}}=\left(f\left(q^{\prime}\right)\left((d-a)-2 \varepsilon q^{\prime}\right)-2 \varepsilon F\left(q^{\prime}\right)\right)
$$

where $(d-a)-2 \varepsilon q^{\prime}$ is bounded by $d-c$ and so negative for high levels of $\varepsilon$. this implies that there is a unique equilibrium.

Total differentiation of the equilibrium condition implies,

$$
\frac{d q}{d r}=\frac{1}{\left(f\left(q^{\prime}\right)\left((d-a)-2 \varepsilon q^{\prime}\right)-2 \varepsilon F\left(q^{\prime}\right)\right)}
$$

Again as shocks become large this is negative. In this equilibrium $\rho=F\left(q^{\prime}\right)$ and so is decreasing in $r$. In this equilibrium $1=\gamma_{R R}>\gamma_{R S}=\frac{F(\underline{q})}{F\left(q^{\prime}\right)}$, these are weakly increasing in $r$.

Finally, in the free rider family of equilibria, the equilibrium conditions are,

$$
\begin{aligned}
q^{\prime} & =\frac{F\left(q^{\prime}\right)}{F\left(q^{\prime}\right)+\alpha} \bar{q}+\left(1-\frac{F\left(q^{\prime}\right)}{F\left(q^{\prime}\right)+\alpha}\right) \underline{q} ; \\
r & =\left(F\left(q^{\prime}\right)-F(\underline{q})\right)(b-a) .
\end{aligned}
$$

Given $r$, as $F($.$) is increasing, there is a unique value of q^{\prime}$ satisfying the second equation. Given this value of $q^{\prime}$, the value of $\alpha$ satisfying the first equation is unique as the right hand side is decreasing in $\alpha$. therefore the equilibrium is unique. In this equilibrium $\rho=F\left(q^{\prime}\right)+\alpha$.

Total differentiation of the second equation yields,

$$
\frac{d q}{d r}=\frac{1}{f\left(q^{\prime}\right)(b-a)}
$$

and for the first equation,

$$
\frac{d \alpha}{d q}(q-\underline{q})=f(q)(\bar{q}-q)-F\left(q^{\prime}\right)-\alpha
$$

Putting these together we get, 


$$
\frac{d\left(F\left(q^{\prime}\right)+\alpha\right)}{d r}=f(q) \frac{d q}{d r}+\frac{d \alpha}{d q}=\frac{1}{(b-a)}+\frac{f(q)(\bar{q}-q)-F\left(q^{\prime}\right)-\alpha}{(q-\underline{q})}
$$

and once again this becomes negative with high levels of shocks. Finally note that for this equilibrium

$$
\begin{aligned}
\gamma_{R R} & =\frac{F\left(q^{\prime}\right)}{F\left(q^{\prime}\right)+\alpha} \\
\gamma_{R S} & =\frac{F(\underline{q})}{F\left(q^{\prime}\right)+\alpha}
\end{aligned}
$$

where by the above $\gamma_{R S}$ is increasing in $r$. To see that $\gamma_{R R}$ is also increasing in $r$, note that by the above $q^{\prime}$ is increasing in $r$.

Proof of Proposition 3: First note that the material benefits of types below $\underline{q}$ are the lowest among all types of individuals and we therefore focus on finding equilibria in which they are better off than in a secular world in which all defect and hence utility is $a$. We now find the equilibrium which offers the best case scenario for these types.

From the proof of proposition 4 , the benefit of these types is increasing in $q^{\prime}$, the cutoff in a full cooperation equilibrium. Consider next the selective cooperation equilibrium. The benefit of type below $q$ is

$$
\begin{aligned}
& F\left(q^{\prime}\right) d+\left(1-F\left(q^{\prime}\right)\right) c-r-a \\
= & \left(1-F\left(q^{\prime}\right)\right)(c-a)+F(\underline{q})(b-a)+2 \varepsilon F\left(q^{\prime}\right) q^{\prime}
\end{aligned}
$$

taking derivative with respect to $q^{\prime}$ we get,

$$
\left.-f\left(q^{\prime}\right)\right)\left(c-a-2 \varepsilon q^{\prime}\right)+2 \varepsilon F\left(q^{\prime}\right)>0
$$

as $q^{\prime}>\frac{c-a}{2 \varepsilon}$.

Consider now equilibria with free riders. The benefit of type below $\underline{q}$ is,

$$
\begin{aligned}
& F\left(q^{\prime}\right) d+\left(1-F\left(q^{\prime}\right)\right) c-r-a \\
= & F\left(q^{\prime}\right)(d-c-b+a)+F(\underline{q})(b-a)+c-a
\end{aligned}
$$

This is also increasing in $q^{\prime}$ and so is maximized at $q^{\prime}=\bar{q}$ which is the limit of the selective equilibria.

Therefore we consider the selective cooperation equilibrium with the largest religion which satisfies

$$
(F(\bar{q})-F(\underline{q}))(b-a)=r
$$


For religious below $\underline{q}$, the benefit of being in this equilibrium rather than in a secular world is

$$
\begin{aligned}
& F(\bar{q}) d+(1-F(\bar{q})) c-r-a \\
= & F(\bar{q})(d-b)+(1-F(\bar{q}))(c-a)+F(\underline{q})(b-a)
\end{aligned}
$$

Note that this expression is increasing in $\varepsilon$ as $\bar{q}$ are $\underline{q}$ increasing in $\varepsilon$ and by the strategic complementarities. We can find a $\mu>0$ and a distribution satisfying $F(\bar{q})(d-b)+F(\underline{q})(b-a)>$ $\mu$ and $(1-F(\bar{q}))<\frac{\mu}{|c-a|}$ for which this utility difference is strictly larger than zero.

Proof of Proposition 5: In the full cooperation religion equilibrium conditions are given by,

$$
F\left(q^{\prime}\right)(d-b)+\left(1-F\left(q^{\prime}\right)\right)(c-a)-2 \varepsilon q^{\prime}=r
$$

In the proof of Proposition 4 we have shown that for high enough shocks the left hand side is decreasing in $q^{\prime}$ implying a unique equilibrium. Note that both increased scientific knowledge and increased economic development imply that the left hand side decreases and hence the resulting new equilibrium will have a higher cutoff $q^{\prime}$.

In a religious organization with selective cooperation the equilibrium condition is,

$$
F\left(q^{\prime}\right)\left((d-a)-2 \varepsilon q^{\prime}\right)-F(\underline{q})(b-a)=r
$$

Again in Proposition 4 we have proved that for high enough $\varepsilon$ the left hand side is decreasing in $q^{\prime}$. Increased economic development (lower $\varepsilon$ ) clearly lowers the left hand side resulting in a new equilibrium with lower participation. We have illustrated in the text why scientific progress has ambiguous effects on religious participation.

In a religious organization with free riders equilibrium conditions are,

$$
\begin{aligned}
q^{\prime} & =\frac{F\left(q^{\prime}\right)}{F\left(q^{\prime}\right)+\alpha} \bar{q}+\left(1-\frac{F\left(q^{\prime}\right)}{F\left(q^{\prime}\right)+\alpha}\right) \underline{q} \\
r & =\left(F\left(q^{\prime}\right)-F(\underline{q})\right)(b-a)
\end{aligned}
$$

Total differentiation with respect to $\varepsilon$ yields

$$
\begin{gathered}
\frac{d q^{\prime}}{d \varepsilon}=\frac{f(\underline{q})}{f\left(q^{\prime}\right)} \frac{|c-a|}{4 \varepsilon^{2}}>0 \\
\frac{d \alpha}{d \varepsilon}=\frac{\frac{d q^{\prime}}{d \varepsilon}\left((\bar{q}-\underline{q}) \frac{f\left(q^{\prime}\right) \alpha}{\left(F\left(q^{\prime}\right)+\alpha\right)}-1\right)-\frac{1}{2 \varepsilon}\left(F\left(q^{\prime}\right) \bar{q}+\left(1-F\left(q^{\prime}\right)\right) \underline{q}\right)}{(\bar{q}-\underline{q}) \frac{F\left(q^{\prime}\right)}{\left(F\left(q^{\prime}\right)+\alpha\right)^{2}}}
\end{gathered}
$$


The size of religious participation is $F\left(q^{\prime}\right)+\alpha$, so the sign effect of economic development on religious participation is given by

$$
\begin{aligned}
& \operatorname{sign}\left(\frac{d F\left(q^{\prime}\right)}{d \varepsilon}+\frac{d \alpha}{d \varepsilon}\right) \\
= & \operatorname{sign}\left(f(\underline{q}) \frac{|c-a|}{4 \varepsilon^{2}}+\frac{f(\underline{q})}{f\left(q^{\prime}\right)} \frac{|c-a|}{4 \varepsilon^{2}}\left(\frac{(\bar{q}-\underline{q}) f\left(q^{\prime}\right)-1}{(\bar{q}-\underline{q}) \frac{F\left(q^{\prime}\right)}{\left(F\left(q^{\prime}\right)+\alpha\right)}}\right)-\frac{1}{2 \varepsilon} \frac{\left(F\left(q^{\prime}\right) \bar{q}+\left(1-F\left(q^{\prime}\right)\right) \underline{q}\right)}{\left.(\bar{q}-\underline{q}) \frac{F\left(q^{\prime}\right)}{\left(F\left(q^{\prime}\right)+\alpha\right)}\right)}\right.
\end{aligned}
$$

Note that for high $\varepsilon$ the first term is insignificant and hence the sign depends on the the relative size of the second and third expressions (which are of conflicting signs). Which of them is greater depends on whether $\frac{f(q)}{f\left(q^{\prime}\right)} \frac{q\left(1-(\bar{q}-q) f\left(q^{\prime}\right)\right)}{\left(F\left(q^{\prime}\right) \bar{q}+\left(1-F\left(q^{\prime}\right)\right) \underline{q}\right)} \lessgtr 1$, where:

$$
\frac{f(\underline{q})}{f\left(q^{\prime}\right)} \frac{\underline{q}\left(1-(\bar{q}-\underline{q}) f\left(q^{\prime}\right)\right)}{\left(F\left(q^{\prime}\right) \bar{q}+\left(1-F\left(q^{\prime}\right)\right) \underline{q}\right)} \simeq \frac{f(\underline{q})}{f\left(q^{\prime}\right)}
$$

and thus it will depend on whether $\frac{f(q)}{f\left(q^{\prime}\right)} \lessgtr 1$.

Proof of Proposition 6: (i) Consider a fully cooperative group, A, and a selective cooperation group, B. If group A is tolerant, all its intermediate types cooperate with group B members, then it must be that all intermediate types of group B will cooperate with members of group A, since it is their best response. Thus, to sustain intolerance between group A and $\mathrm{B}$, it must be that the group $\mathrm{A}$ is intolerant.

(ii) We now construct an equilibrium with two religions with the following characteristics:

$$
1=\gamma_{R^{2} R^{2}}>\gamma_{R^{1} R^{2}}>\gamma_{R^{1} R^{1}}=\gamma_{R^{2} R^{1}}>\gamma_{R^{1} S}>0
$$

In particular, in this equilibrium, all $R^{1}$ agents which cooperate in $R^{1}$ also cooperate with agents in $R^{2}$, whereas the opposite is not true, as agents in $R^{2}$ enjoy full internal cooperation but some of them defect against members of $R^{1}$.

Let $q_{I J}$, where $I \in\left\{R^{1}, R^{2}\right\}$ and $J \in\left\{R^{1}, R^{2}, S\right\}$ be the cutoff above which individuals who are in $I$ will defect against people in $J$. In equilibrium we have $\bar{q}=q_{R^{2} R^{2}}>q_{R^{1} R^{2}}>$ $q_{R^{1} R^{1}}=q_{R^{2} R^{1}}>\underline{q}$. Religious individuals with $q^{i} \leq \underline{q}$ and will cooperate with all. Religious individuals with $q^{i} \in\left(\underline{q}, q_{R^{1} R^{1}}\right)$, will defect against seculars and cooperate otherwise. Religious individuals, in $\left(q_{R^{1} R^{1}}, q_{R^{1} R^{2}}\right)$, will, when in $R^{1}$ or $R^{2}$, cooperate only with $R^{2}$ members, and defect otherwise. Religious individuals in $\left(q_{R^{1} R^{2}}, \bar{q}\right]$, when in $R^{2}$ will cooperate only with $R^{2}$ members, and will defect otherwise. Finally, religious individuals with $q^{i}>\bar{q}$, will defect against all. Note that for all these types, the benefit from joining $R^{2}$ is always greater than the benefit from joining $R^{1}$, as they will enjoy a higher level of cooperation from society overall.

We set $r_{1}=\left(F\left(q_{R^{1} R^{1}}\right)-F(\underline{q})\right)(b-a)$ and $r_{2}=\left(F\left(q_{R^{1} R^{1}}\right)-F(\underline{q})\right)(b-a)+\left(F\left(q_{R^{1} R^{2}}\right)-\right.$ $\left.F\left(q_{R^{1} R^{1}}\right)\right)(d-c)>r_{1}$. This implies that religious agents with $q^{i}<q_{R^{1} R^{2}}$ strictly prefer to 
be religious than to be secular, but are indifferent with regard to which religion to join. On the other hand, types with $q^{i}>q_{R^{1} R^{2}}$ are indifferent between joining $R^{1}$ and being secular, and strictly prefer it to joining $R^{2}$. We can therefore consider an equilibrium in which $R^{1}$ includes a mass $\alpha$ of the types with $q^{i} \leq q$, all types in $\left(q, q_{R^{1} R^{1}}\right)$, and a mass $\phi$ of types with $q^{i}>q_{R^{1} R^{2}}$, and in which $R^{2}$ includes the remaining share of the types with $q^{i} \leq \underline{q}$ and all types in $\left(q_{R^{1} R^{1}}, q_{R^{1} R^{2}}\right)$. The remaining agents are secular. The equations for the cutoff points are:

$$
\begin{aligned}
& q_{R^{1} R^{1}}=\gamma_{R^{1} R^{1}} \bar{q}+\left(1-\gamma_{R^{1} R^{1}}\right) \underline{q} ; \\
& q_{R^{1} R^{2}}=\gamma_{R^{1} R^{2}} \bar{q}+\left(1-\gamma_{R^{1} R^{2}}\right) \underline{q}
\end{aligned}
$$

this implies,

$$
\begin{aligned}
q_{R^{1} R^{1}} & =\frac{F\left(q_{R^{1} R^{1}}\right)-F(\underline{q})+\alpha}{F\left(q_{R^{1} R^{1}}\right)-F(\underline{q})+\alpha+\phi}(\bar{q}-\underline{q})+\underline{q} \\
q_{R^{1} R^{2}} & =\frac{F(\underline{q})-\alpha}{F\left(q_{R^{1} R^{2}}\right)-F\left(q_{R^{1} R^{1}}\right)+F(\underline{q})-\alpha}(\bar{q}-\underline{q})+\underline{q}
\end{aligned}
$$

Note that to solve for an equilibrium, we simply need to find $\alpha$ and $\phi$ such that the solution for the above fixed points equations (note that we first solve for $q_{R^{1} R^{1}}$ and then for $q_{R^{1} R^{2}}$ ), will satisfy the following conditions:

$$
\begin{aligned}
& 1>\gamma_{R^{1} R^{2}}>\gamma_{R^{1} R^{1}}>\gamma_{R^{1} S}>0 \\
& 0<\alpha<F(\underline{q}) ; 0<\phi<1-F\left(q_{R^{1} R^{2}}\right)
\end{aligned}
$$

Consider the uniform distribution on $[-1,1]$, i.e., $F(q)=\frac{1}{2}(1+q)$. Let $\bar{q}=-0.25$ and let $\underline{q}=-0.5$. Finally, let $\alpha=0.2$ and let $\phi=0.3$. The solution is is $q_{R^{1} R^{1}}=-0.38446, q_{R^{2} R^{1}}=$ -0.33393 and it satisfies all the conditions set above.

Proof of Lemma 1: Suppose that an individual cooperated in the game (the analysis for an individual who defected is analogous). Note that such an individual will only update his belief about $q_{c}$. His updated beliefs satisfy, for any $q_{c}^{\prime} \geq q_{c}^{\prime \prime}$ :

$$
\frac{\operatorname{Pr}\left(q_{c}^{\prime} \mid-\varepsilon\right)}{\operatorname{Pr}\left(q_{c}^{\prime} \mid \varepsilon\right)}=\frac{\frac{f\left(q_{c}^{\prime}\right) q_{c}^{\prime}}{\int f\left(q_{c}\right) q_{c} d q_{c}}}{\frac{f\left(q_{c}^{\prime}\right)\left(1-q_{c}^{\prime}\right)}{\int f\left(q_{c}\right)\left(1-q_{c}\right) d q_{c}}} \geq \frac{\frac{f\left(q_{c}^{\prime \prime}\right) q_{c}^{\prime \prime}}{\int f\left(q_{c}\right) q_{c} d q_{c}}}{\int f\left(q_{c}^{\prime \prime}\right)\left(1-q_{c}^{\prime \prime}\right)}=\frac{\operatorname{Pr}\left(q_{c}^{\prime \prime} \mid-\varepsilon\right)}{\operatorname{Pr}\left(q_{c}^{\prime \prime} \mid \varepsilon\right)} .
$$

The MLRP therefore holds, implying the result reported in Lemma 1. 